\title{
THE CHALLENGE OF GENDER RE-ASSIGNMENT IN A FEMALE PSEUDO-HERMAPHRODITE IN A RESOURCE POOR SETTING: A CASE REPORT
}

Olopade O. B ${ }^{1}$, Yusuf A. $\mathrm{O}^{1}$, Mosanya J.T ${ }^{2}$, Oluwatoke O. $\mathrm{O}^{1}$, Adesokan O. A , Ajani G.O.D. ${ }^{3}$

LAUTECH Teaching Hospital, Osogbo Osun State, Nigeria.

One of the rarely documented endocrine disorders in African setting is pseudo-hermaphroditism. Female pseudohermaphroditism (virilized female) is characterized by the presence of 46XX karyotype, ovaries, normal mullerian duct structures, absent wolffian duct structures and virilised genitalia due to exposure to androgens in-utero. The commonest cause is Congenital Adrenal Hyperplasia.

To highlight the challenges in investigating and managing female pseudo-hermaphroditism in a resource-limited setting.

Twenty-one year-old male secondary school drop-out referred from a secondary health facility on account of recurrent bilateral loin pain of 5 months duration with ultrasound scan report of bilateral small testes. Pain was located in the right iliac fossae radiating to the groin and cyclical lasting for about 14 days per month. There is history of small penis and progressive enlargement of both breasts at puberty. He is the $2^{\text {nd }}$ of a set of twins. The second twin is a female who has given birth to a male child. Physical Examination revealed a young man with no beard, sparse axillary hair, fully developed breasts, (Tanner stage $\mathrm{V}$ ), female escutcheon, micropenis. Penile length $=4 \mathrm{~cm}$, right testis $<2 \mathrm{mls}$, left scrotal sac was empty. His height $=157 \mathrm{~cm}$, weight $=47.5 \mathrm{~kg}$ and $\mathrm{BMI}=19.27 \mathrm{~kg} / \mathrm{m}^{2}$. Pelvic ultrasound scanning revealed intact uterus with fallopian tubes and right ovary.

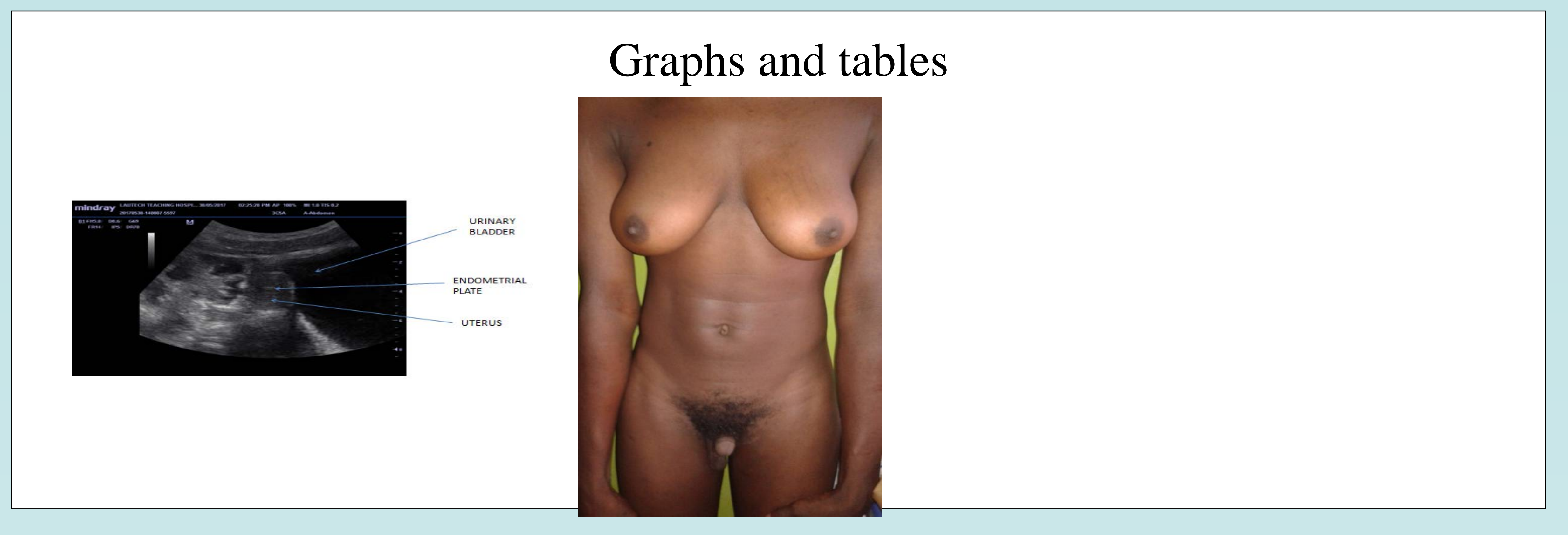

Sexual differentiation disorder is a complex entity which requires good clinical skill and patience to help the affected individual. Sexual differentiation disorders are usually detected in childhood, which is at variance with our index case. No abnormality was detected at birth and by the time the patient noticed breast development during his early teenage period, he was already living with his grandmother due to parental separation. The cyclical abdominal pain on monthly basis with female phenotypic appearance made our patient to be psychologically disturbed and confused since he was raised as a boy from childhood. Sudden discovery by the father of the patient necessitated various traditional treatments and religious deliverances months before presentation in a health facility.

The definitive diagnosis could not be made due to inability to do karyotyping and other biochemical enzymes assays such as 17- hydroxyprogesterone, 11-deoxycortisol and dehydroepiandrosterone (DHEA) that could pointers to the diagnosis because these tests were not affordable for the patient and no facility to do all required investigations in our centre. The presence of right testis found on ultrasound in the inguinal canal signifies non disappearance of the wolffian duct structures during embryogenesis; making diagnosis difficult and complex. Our index patient tends towards intersex than Virilized female but this cannot be substantiated in view of the numerous challenges of investigating and proper management in a resource deprived community.

Gender re-assignment in our environment is extremely challenging as there are many factors to be considered such as patient wish, influence(s) of the parent and relatives, financial constraints (as patients pay out of pockets for health care), cultural norms, religious and environmental issues.

Gender re-assignment requires multi-disciplinary approach but the patient is faced with financial, social, cultural and religious barriers. The sex of rearing of this index case for the past 21years is strongly at variance with the true sex of the patient thus resulting in psychological trauma and gender confusion at counseling. It will be of great help if there can be special grant to support endocrinologists in developing countries in investigating and managing peculiar endocrine disorders such as this

\section{References:}

Jason N Boussin L, Knebelman B, et al. Anti-mullerian hormone and intersex states. Trends Endocrinol Metab. $1991 ; 2: 227$.

Warne GL,Kanumakala S: Molecular endocrinology of sex differentiation. Semin Reprod Med.2002; 20(3):169. Warne GL. Long term outcome of disorders of sex development. Sex Develop 2008; 2; 